\title{
TRANSFER OF LEARNING IN POSTGRADUATE MANAGEMENT PROGRAMMES
}

\author{
Patrícia Teixeira Maggi-da-Silva and Diógenes de Souza Bido \\ Universidade Presbiteriana Mackenzie, Rua da Consolação, 930 - São Paulo SP, Brazil
}

\begin{abstract}
There is an increased recognition by the organizations of the need to analyze the results of investments in different types of formal learning. By investing in formal learning, organizations need to assess whether individuals are transferring what they have learned through behavioral changes at work. However, they don't know how to do so, leading to the problem or gap of learning transfer. In addition, there is a need to better define and operationalize the construct learning transfer and present the differences between transfer as use and as efficiency. Although, there is an increase number of academic research on learning transfer, there is a scarcity of studies including long-term courses offered by higher education institutions. In this study we developed and tested a comprehensive model of transfer of learning in a context of postgraduate management programmes. Based on the taxonomy of use proposed by Yelon et al. (2014), we operationalized the dependent variable transfer as use as a second order latent variable with five dimensions. The model also includes five independent variables: transfer design, critical reflection, organizational cynicism, job autonomy and learning culture. We tested the hypotheses with a sample of 424 students and graduates of postgraduate management programmes in Brazil. Data were submitted to descriptive statistical analysis and multivariate techniques, including correlations, Confirmatory Factor Analysis (CFA), and Structural Equation Modeling (SEM) for hypothesis testing. The results confirmed three of the five hypotheses that predicted direct relationships with the dependent variable: critical reflection, transfer design and learning culture.
\end{abstract}

\section{KEYWORDS}

Learning Transfer, Learning Transfer as Use, Management Education Programmes, MBA, Structural Equation Modeling (SEM)

\section{INTRODUCTION}

Investments in different types of formal learning, which include training, courses, educational programs, among others, have been growing in Brazil and in other countries. This fact suggests that organizations evaluate formal learning positively. However, studies have shown controversial results regarding the real benefits of formal learning for organizations. These results may be partly explained by the difficulties in isolating the effects of formal learning from other factors (NOE et al., 2014). By investing in formal learning, organizations need to assess whether individuals are transferring what they have learned through behavioral changes at work. However, they do not know how to do so, leading to the problem or gap of learning transfer (Hutchins et al., 2010; Volet, 2013). Learning transfer is defined as the application or use at work of knowledge and skills acquired in different types of formal learning. From an academic perspective, studies of learning transfer have advanced from the seminal model and concept proposed by Baldwin and Ford (1988). This model considers that learning transfer is influenced by three main antecedents: (1) The characteristics of the trainee or student; (2) The design of the training; and (3) The work environment. Most empirical research and literature reviews following this seminal model have maintained these three antecedents.

In the last decades, the number of academic studies in learning transfer has increased (Baldwin et al., 2017; Poell, 2017; Segers \& Gegenfurtuner, 2013), demonstrating its theoretical and practical importance. However, the literature still has some gaps, two of which stand out: (1) the definition and operationalization of the construct learning transfer and its differentiation between use and effectiveness; and (2) the scarcity of research in long-term educational programs offered by higher education institutions. 
This study intends to fill these two gaps. For the first, a measure of transfer as use was developed based on the taxonomy proposed by Yelon et al., (2014) and for the second one, the object of inquiry was management specialization courses, which are open and long-term educational programs.

This study follows the learning transfer literature, in which predominate quantitative models, testing the relationships between different antecedents (Lancaster et al., 2013). Based on the literature review, the antecedent variables were selected according to two criteria: (1) Variables that have been little explored in transference research (Baldwin et al., 2009): critical reflection and organizational cynicism; and (2) Conditions in which the selected variables may exert the greatest influence on the relationship with the type of formal learning (Grossman \& Salas, 2011): transfer design, job autonomy and learning culture.

The general objective of this study is: To propose and test a learning transfer model in postgraduate management courses, assessing the simultaneous influence of organizational cynicism, critical reflection, transfer design, job autonomy and learning culture on learning transfer.

This is the first research to test a comprehensive learning transfer model with a sample of students and graduates of management courses in Brazil, using measures developed and tested in previous studies (critical reflection, transfer design, organizational cynicism, job autonomy and learning culture), as well as the development of the scale to measure the learning transfer as use. It is noteworthy the originality of this study, since no research was found in the international and national literature with the antecedents presented in the conceptual model proposed here, including the analysis of the moderating effects.

The main theoretical contribution of this study is the development and testing of the learning transfer as use measure. This five-dimensional scale related to five different uses proves that students can use what they have learned to perform, explain, assess, instruct, and lead. In other words, the knowledge and skills learned in management courses can be used in different ways in the organization, which increases the possibility of these courses to contribute to organizational practices, as well as minimizing the issue of intangibility and difficulties in isolating the formal learning outcomes from other factors. The different uses show that the courses, including MBAs, despite the criticism they have suffered, present contributions to individuals and organizations as well.

\section{BODY OF PAPER}

\subsection{Learning Transfer as Use}

According to Yelon et al. (2014), transfer as use occurs when the student employs something he learned in training to a specific purpose. The concept of use considers the personal choices of relatively autonomous professionals, when they make a decision about when, what and how to use what they have learned. Yelon et al. (2014) developed a taxonomy of use as a multidimensional construct (Figure 1).

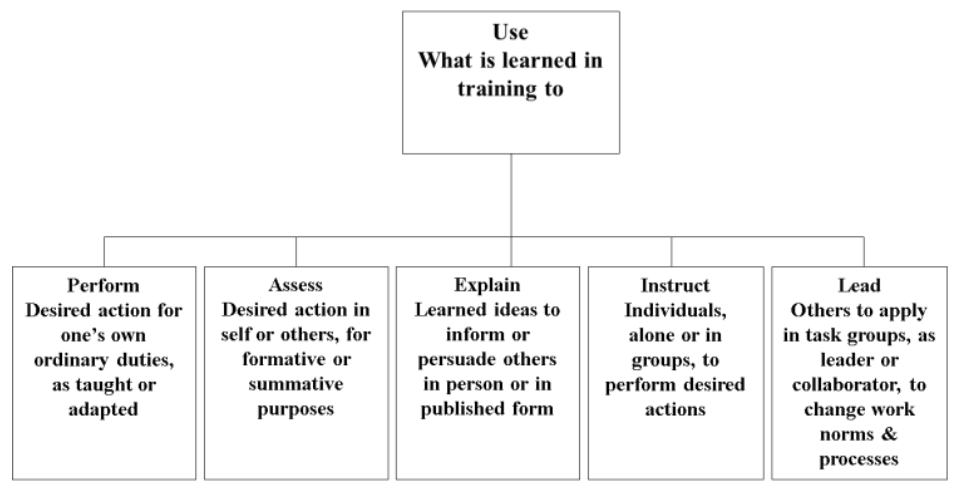

Figure 1. Taxonomy of use

Source: Yelon, Ford and Bhatia (2014) 


\subsection{Research Model and Hypothesis}

This study proposed and tested the research model presented in Figure 2.

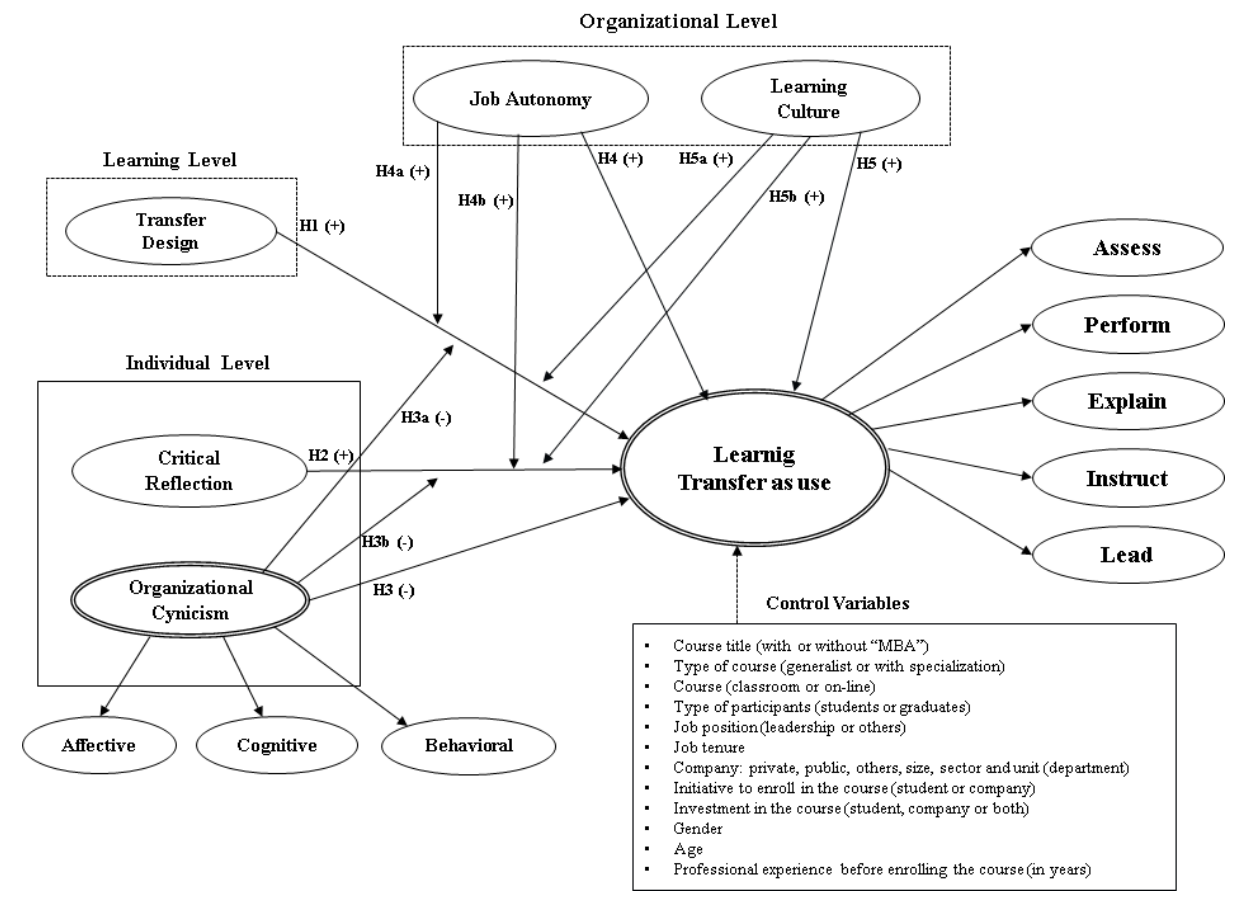

Figure 2. Research Model

Source: Authors

\subsection{Method and Research Design}

\subsubsection{Setting}

This is cross-sectional study conducted in the setting of Brazilian Postgraduate Management Programmes, in which there are basically two types of courses: (1) Courses with the title of MBA; and (2) Courses without the title of MBA. The research was carried out during the first semester of 2019. We selected the participants according to two criteria: (1) graduates who had already concluded the course in 2018 and (2) students who finish the course in 2019 (first or second semesters).

\subsubsection{Instruments}

Participants filled in a self-report questionnaire including the measures presented in Table 1. In addition, the questionnaire contains 21 questions related to demographic, organizational and courses characteristics variables that were analyzed as control variables.

All measures related to the independent variables were based on instruments validated in previous studies. Some of them were translated to Portuguese and back-translated and others had been previously translated and tested in the Brazilian context. For the dependent variable learning transfer as use, we developed a measure based on the taxonomy of use proposed by Yelon et al. (2014). All measures were assessed by Brazilian researchers, who have academic experience in topics related to the object of inquiry as well as quantitative methods. In addition, the dependent variable measure was tested in a previous study in a sample of 80 participants, including students and graduates of MBA programmes. 
Table 1. Measures

\begin{tabular}{llc}
\hline Measures & Studies & $\begin{array}{l}\text { Number } \\
\text { of indicators }\end{array}$ \\
\hline Transfer Design & Holton, Bates e Ruona (2000) & 4 \\
Critical Reflection & Kember et al. (2000) & 4 \\
Job Autonomy & Nijman et al. (2006) & 4 \\
Learning Culture DLOQ-A & Marsick and Watkins (2003) & 7 \\
Organizational Cynicism & Dean; Brandes; Dharwadkar (1998) & 13 \\
Learnig Transfer as use & Developed and tested by the authors & 15 \\
\hline
\end{tabular}

\subsubsection{Data Analyses}

The data were analyzed in three steps: (1) Descriptive Statistics; (2) Confirmatory Factor Analyses (CFA) in order to assess the measurement model (convergent, discriminant construct validity and reliability); and (3) Hypotheses testing. The structural model was estimated by PLS-SEM - Partial Least Squares Structural Equation Modeling, using the software SmartPLS v.3.2.8 (Ringle et al., 2017).

\subsection{Results}

\subsubsection{Sample}

With respect to the demographic profile, 67 per cent of the respondents were in the 25-35 age group and 53 per cent were male. In addition, 41 per cent had more than 10 years of professional experience before enrolling the course, 92 per cent were students still having classes when the research was carried out, 93 per cent of respondents had the initiative to start the course, 74 per cent pay the course with their own financial resources. The majority of respondents work in large-sized (71\%) private companies $(97 \%)$, for more than four years $(51 \%)$. About 55 per cent are courses with specialization and 74 per cent are courses with the title of MBA.

\subsubsection{Measurement Model}

In order to assess the measurement model (convergent validity, discriminant validity and reliability), the results were analyzed in two steps: (1) all constructs as first order variables (Table 2); and (2) Organizational Cynicism and Use as second order variables (Table 3 ).

Table 2. Correlations among first order latent variables

\begin{tabular}{|c|c|c|c|c|c|c|c|c|c|c|c|c|c|c|}
\hline First order Latent Variable & $\mathbf{M}$ & SD & 1 & 2 & 3 & 4 & 5 & 6 & 7 & 8 & 9 & 10 & 11 & 12 \\
\hline 1. JOB AUTONOMY & 5,32 & 1,45 & 0,790 & & & & & & & & & & & \\
\hline 2. AFFECTIVE & 3,62 & 1,70 & $-0,360$ & 0,792 & & & & & & & & & & \\
\hline 3. COGNITIVE & 3,70 & 1,75 & $-0,299$ & 0,686 & 0,801 & & & & & & & & & \\
\hline 4. BEHAVIORAL & 2,78 & 1,72 & $-0,287$ & 0,600 & 0,719 & 0,809 & & & & & & & & \\
\hline 5.TRANSFER DESIGN & 4,99 & 1,16 & 0,099 & $-0,104$ & $-0,160$ & $-0,183$ & $\mathbf{0 , 8 4 4}$ & & & & & & & \\
\hline 6. LEARNING CULTURE & 4,54 & 1,68 & 0,386 & $-0,466$ & $-0,620$ & $-0,464$ & 0,189 & 0,769 & & & & & & \\
\hline 9. PERFORM & 4,45 & 1,45 & 0,133 & $-0,031$ & $-0,036$ & $-0,124$ & 0,547 & 0,201 & 0,556 & 0,791 & 0,869 & & & \\
\hline 10. EXPLAIN & 4,63 & 1,68 & 0,114 & $-0,002$ & 0,012 & $-0,035$ & 0,390 & 0,169 & 0,403 & 0,676 & 0,657 & 0,819 & & \\
\hline 11. INSTRUCT & 4,26 & 1,66 & 0,110 & 0,007 & 0,000 & $-0,078$ & 0,413 & 0,180 & 0,438 & 0,770 & 0,755 & 0,799 & 0,872 & \\
\hline 12. LEAD & 4,19 & 1,71 & 0,232 & $-0,089$ & $-0,107$ & $-0,178$ & 0,467 & 0,277 & 0,425 & 0,667 & 0,690 & 0,562 & 0,697 & $\mathbf{0 , 9 0 9}$ \\
\hline \multicolumn{3}{|c|}{ Average Extracted Variance (AVE) } & 0,624 & 0,627 & 0,642 & 0,654 & 0,713 & 0,592 & 0,707 & 0,718 & 0,756 & 0,670 & 0,761 & 0,826 \\
\hline
\end{tabular}

Note: All constructs were measured using a 7 point Likert Scale (1 to 7 ) 
Table 3. Correlations among second order latent variables

\begin{tabular}{|c|c|c|c|c|c|c|c|c|}
\hline Second order Latent Variable & $\mathbf{M}$ & SD & 1 & 2 & 3 & 4 & 5 & 6 \\
\hline 1. JOB AUTONOMY & 5,32 & 1,16 & 0,789 & & & & & \\
\hline 2. LEARNING CULTURE & 4,54 & 1,68 & 0,391 & 0,769 & & & & \\
\hline 3. ORGANIZATIONAL CYNICISM & 3,4 & 1,79 & $-0,350$ & $-0,577$ & 0,869 & & & \\
\hline 4. TRANSFER DESIGN & 4,99 & 1,16 & 0,103 & 0,192 & $-0,167$ & 0,844 & & \\
\hline 5. CRITICAL REFLECTION & 5,71 & 1,24 & 0,098 & 0,100 & $-0,038$ & 0,523 & 0,841 & \\
\hline 6. USE & 4,32 & 1,65 & 0,155 & 0,222 & $-0,054$ & 0,532 & 0,532 & 0,875 \\
\hline \multicolumn{3}{|c|}{ Average Extracted Variance (AVE) } & 0,622 & 0,592 & 0,755 & 0,713 & 0,707 & 0,765 \\
\hline \multicolumn{3}{|c|}{ Composite Reliability } & 0,867 & 0,910 & 0,902 & 0,908 & 0,906 & 0,942 \\
\hline \multicolumn{3}{|c|}{ Cronbach's Alpha } & 0,803 & 0,884 & 0,838 & 0,865 & 0,862 & 0,945 \\
\hline
\end{tabular}

Note: All constructs were measured using a 7 point Likert Scale (1 to 7)

According to Tables 2 and 3, the AVE values are superior to 0,5 indicating convergent validity among the constructs. The values in the diagonal of Tables 2 and 3 are the square root of the AVE. As these values are superior than the correlations (values outside the diagonal), there is discriminant validity among the constructs. We also analyzed the cross-loadings matrix (not presented here due to space limitation) and all loadings were superior to 0,71 in their latent variables, indicating convergent and discriminant validity among the indicators. So, these results confirmed that there are convergent validity and discriminant validity when Organizational Cynicism and USE are measured as first and as second order latent variables (Hair Jr. et al., 2016).

\subsubsection{Structural Model}

The structural model was analyzed in three steps: (1) all control variables; (2) only the control variables statistically significant and the complete model. The final results are presented in Table 4.

Table 4. Complete structural model

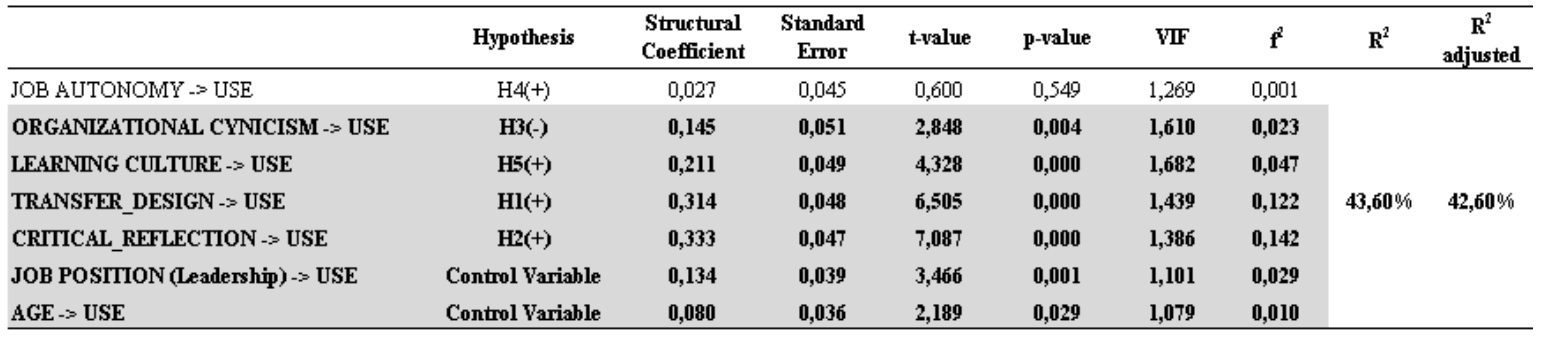

Note 1: t-values and p-values were estimated by bootstrap with 5.000 resampling.

Nota 2: Values in bold contain the significant coefficients.

Nota 3: Reference values to size effects $\left(\mathrm{f}^{2}\right): 0,02=$ small; $0,15=$ medium; e $0,35=$ big (Hair Jr. et al., 2016).

Although the structural coefficient of Hypothesis $\mathrm{H} 3$ was statistically significant, $\mathrm{H} 3$ was not confirmed because according to literature review organizational cynicism will be negatively associated to USE. Hypotheses H1 (+), H2 (+) and H5 (+) were confirmed.

We also analyzed the moderator effects, but none of them were statistically significant, so all the moderation hypotheses were not confirmed: Hypotheses H3a (-), H3b (-), H4a (+), H4b (+), H5a (+) and H5b (+).

\section{CONCLUSION}

This study contributes to organizations and general and to High Education Institutions. It shows that the courses in the Brazilian context bring contributions to individuals and to companies no matter they invest in log-term courses to develop their employees. Additionally, the measure of use can be adapted to different types of formal learning (including hard skills and soft skills), and in models with different predictors.

As a limitation, given the cross-sectional nature of this study, it is not possible to establish causal inferences. 


\section{ACKNOWLEDGEMENT}

This research was possible with support provided by CAPES (Coordenação de Aperfeiçoamento de Pessoal de Nível Superior) and CNPq (Conselho Nacional de Desenvolvimento Científico e Tecnológico).

\section{REFERENCES}

Baldwin, T. T., \& Ford, J. K. (1988). Transfer of training: a review and directions for future research. Personnel Psychology, 41(1), 63-105.

Baldwin, T. T., Ford, K., \& Blume, B. D. (2009). Transfer of training 1988-2008: an updated review and agenda for future reasearch. International Review of Industrial and Organizational Psychology, 24, 41-70.

Baldwin, T. T., Ford, J. K., \& Blume, B. D. (2017). The State of Transfer of Training Research: Moving Toward More Consumer-Centric Inquiry. Human Resource Development Quarterly, 28(1), 17-28.

Grossman, R., \& Salas, E. (2011). The transfer of training: what really matters. International Journal of Training and Development, 15(2), 103-120.

Hair Jr., J. F.; Hult, G. T. M.; Ringle, C. M.; Sardstedt, M. (2016). Primer on Partial Least Squares Strucutural Equation Modeling (PLS-SEM). $2^{\mathrm{a}}$ ed. Thousand Oaks, CA: Sage Publications, Inc.

Hutchins, H. M.; Burke, L. A.; Berthelsen, A. M. (2010). A missing link in the transfer problem? Examining how trainers learn about training transfer. Human Resource Management, 49, 599-618.

Lancaster, S.; Di Milia, L; \& Cameron, R. (2013). Supervisor Behaviors that facilitate training transfer. Journal of Workplace Learning, 25(1),.6-22.

Noe, R. A.; Clarke, A. D. M.; \& Klein, H. J. Learning in the twenty-first century- workplace. (2014). Annual Review of Organizational Psychology and Organizational Behavior, 1(1), 245-275.

Poell, R. F. (2017). Time to 'Flip' the Training Transfer Tradition: employees create learning paths strategically. Human Resource Development Quarterly, 28(1), 9-15.

Ringle, C. M.; Wende, S.; \& Becker, J. M. "SmartPLS 3." Boenningstedt: SmartPLS GmbH. Available in: <http://www.smartpls.com>.

Segers, M. R.; \& Gegenfurtuner, A. (2013). Transfer of training: New conceptualizations through integrated research perspectives. Educational Research Review, 8(1),1-4.

Volet, S., (2013). Extending, broadening and rethinking existing research on transfer of training. Educational Research Review, 8, 90-95.

Yelon, S.; Ford, J. K.; \& Bhatia, S. (2014). How trainees transfer what they have learned: Toward a taxonomy of use. Performance Improvement Quarterly, 27(3), 27-52. 